\title{
Medical Device Donation Practices in Canada: A Survey of Donor and Recipient Perspectives
}

\author{
By B. Bradley', C. Yoon², S. Zahedi², Y. Adusei-Poku', J. Zienaa ${ }^{3}$, N. Adjabu³, Y. Cheng' ', W. Gentles ${ }^{4}$, \\ ${ }^{1}$ Centre for Global Engineering and the Department of Chemical Engineering and Applied Chemistry, University of Toronto, \\ Toronto, Canada \\ ${ }^{2}$ Institute of Biomaterials and Biomedical Engineering, University of Toronto, Toronto, Canada \\ ${ }^{3}$ Ghana Health Service, Ghana, Africa \\ ${ }^{4}$ The Canadian Medical and Biological Engineering Society, Ottawa, Canada
}

\begin{abstract}
Background and Objective: Although developing countries have been receiving donations of medical equipment for many years, a number of studies have indicated that a high percentage of donated equipment is never put into use. ${ }^{1,3,4}$ Many of the reasons for this can be traced back to inadequate donation practices on the part of donor organizations. The objective of this study was to gain an improved understanding of the practices and challenges associated with medical equipment donations by Canadian charitable organizations.

Material and Methods: Forty-one organizations (registered and non-registered charities, non-governmental organizations (NGOs), non-profit organizations, medical clinics, and hospitals) completed an online survey, and 16 respondents were interviewed via telephone or in person. In addition, representatives from 28 hospitals in Ghana were interviewed in person to gain an understanding of the recipient experience.

Results: We observed that for many Canadian donor organizations there is room for improvement in formalizing procedures, testing to verify equipment functionality before shipping, providing additional support for recipients in the form of manuals, spare parts and training, and long-term monitoring of donated items to measure effectiveness. For recipients, the most common challenges faced were lack of spare parts, and lack of operating or service manuals. Despite these challenges, all of the Ghanaian survey respondents said that donated medical equipment benefited their hospitals.

Conclusion: We concluded that because of staffing limitations in smaller donor organizations, and in order to better meet the needs of recipients, it would be beneficial for Canadian organizations to communicate and collaborate with one another to share resources and expertise when planning donations overseas.
\end{abstract}

Keywords - Medical equipment donations, Low resource settings, Canada, Ghana, Best practices. 


\section{INTRODUCTION}

Previous reports have estimated that as much as $40 \%$ to $70 \%$ of medical equipment in developing countries is out of service or never put into use. 1,3,4 The reasons for this include a lack of infrastructure and resources (including spare parts and accessories), poor health technology management, and lack of training. ${ }^{3}$ Given that so many developing countries rely on medical equipment donations, donations that meet recipient needs are crucial to mitigating these challenges and reducing the burden of non-functional equipment.

In the past two decades, numerous guidelines for the donation of medical equipment to low resource countries have been published. ${ }^{2,4,11,12}$ Despite the existence of these guidelines, recent studies suggest that equipment donation practices are a continuing problem. For example, a study in Tanzania found that $78 \%$ of surveyed staff in a national hospital were dissatisfied with the quality of donated medical equipment, citing lack of supporting manuals and training, poor communication between the donor and the hospital, lack of clear equipment specifications, unneeded equipment, and poor donor planning as reasons for their dissatisfaction. ${ }^{5}$ A case study about a donation of oxygen concentrators to The Gambia demonstrates how something as simple as a mismatch in electrical requirements can lead to unusable equipment, not to mention wasted effort. ${ }^{6}$

While many organizations across Canada donate medical equipment and supplies to developing countries, no previous study has explored the donation practices of these organizations. The objectives of this study were: (a) to determine the scope of medical equipment donations by Canadian charitable organizations, and better understand their specific donation practices and challenges; (b) to interview representatives of recipient health facilities in Ghana, and learn from their experiences; and (c) to disseminate good practice guidance to donating organizations in Canada and around the world. This study was initiated by the International Outreach Committee of the Canadian Medical and Biological Engineering Society (CMBES), which has had a long-standing partnership with the Ghana Biomedical Engineering Association to support clinical engineering capacity in Ghana. ${ }^{7}$

\section{METHODS}

\section{Canadian study}

Canadian organizations actively engaged in the donation of medical equipment and/or supplies to developing countries were surveyed using an online survey tool. Follow-up interviews were conducted with a subset of surveyed organizations. The list of prospective study participants was compiled through project partner connections and networks, Internet search, and through Canada's registered charity search engine. ${ }^{8}$ This phase of research resulted in a database of approximately 80 registered and non-registered charities, non-governmental organizations (NGOs), non-profit organizations, medical clinics, and hospitals.

Organizations were then contacted by telephone and informed of our study and survey. Organizations that were actively donating medical equipment were sent a link to a survey in a follow-up email. The online survey consisted of 20 multiple choice and short answer questions, grouped into the following categories: (a) general organization information; (b) process for determining recipient needs; (c) communication involved in planning donations; (d) sources of equipment; (e) process for verifying quality and safety before shipping equipment; and (f) follow-up methods for evaluating success of the donations. Forty-one organizations completed the survey.

From the organizations that participated in the survey, a list of 16 organizations was identified for follow-up interviews. The short list of organizations was strategically selected to cover a wide geographic range across Canada, as well as a range in size of operations. The goal of the interviews was to gain a deeper understanding of different organizational processes. Sixteen interviews of approximately one hour duration were conducted. Interviews were conducted in person when possible, and by phone otherwise. The breakdown by province (in-person; phone) was as follows: British Columbia $(3 ; 1)$, Saskatchewan $(0 ; 1)$, Ontario $(2 ; 2)$, Quebec $(2 ; 0)$, Maritime provinces $(4 ; 1)$. The research protocol, survey tool and interview question guide were approved by the Office of Research Ethics at the University of Toronto. 


\section{Ghanaian study}

A second survey, consisting of 35 questions, was developed to gather information from Ghanaian hospitals about their experiences receiving medical equipment donations. Four questions collected information about the respondent. The remaining questions were a mix of multiple choice questions and open-ended long answer questions on topics such as: types of medical equipment received, communication with the donor before and after the donation, discussion of equipment needs, level of support from donors in terms of provision of training, manuals and supplies, maintenance and availability of spare parts for donated equipment, logistics such as shipping and customs, and common challenges encountered with donations.

A geographically representative sample of 28 health facilities was chosen for the survey; at least two facilities were visited in each of Ghana's ten regions. We also sought to ensure that facilities receiving donations from Canadian organizations were well represented in the sample (14 out of 28), and that a range of different hospital types was chosen (government, teaching, mission, etc.). Since many hospitals did not have reliable access to the Internet, surveys were administered in person and on paper by a research assistant ("surveyor") rather than online. In some cases, the surveyor waited for respondents to complete the survey, while in other cases the survey was administered as an interview with the surveyor filling in responses.

The research assistant in Ghana was supervised by the Deputy Director, Clinical Engineering Department, Ghana Health Service. Before conducting the survey, all respondents were given an introductory letter explaining the project.

\section{FINDINGS}

The types of Canadian organizations that donate equipment include NGOs, registered charities, and healthcare institutions. Some donor organizations have been in operation for over 25 years (one for almost five decades), others are much newer (five years or less) or are just receiving charitable status. To date, these organizations have provided critical medical equipment to 48 countries around the world (Fig. 1). The most common recipient countries were Haiti, Cuba, Guatemala, and the Philippines.

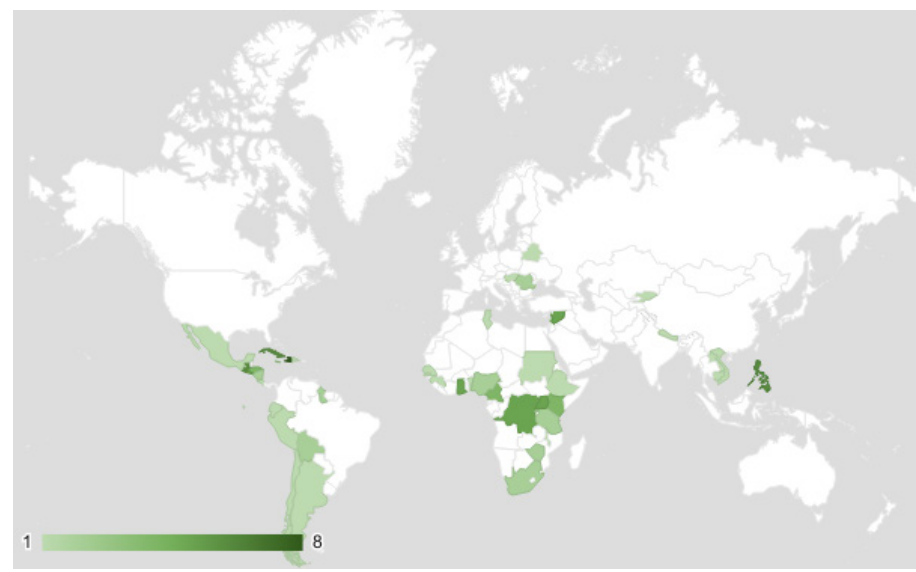

FIGURE 1. Global distribution of recipient countries. Shading indicates number of surveyed Canadian organizations that send equipment to these countries.

From simple frontline equipment (e.g. thermometers, blood pressure monitors, pulse oximeters) to more complex and larger devices (e.g. x-ray, ultrasound machines) Canadian donations help address everything from basic healthcare to supporting a healthy community. Medical devices and consumables are the most commonly donated items, although clinical laboratory and dental equipment, and other items including pharmaceuticals, vehicles and computers, have also been provided as part of donation activities (Fig. 2a). Supplies and small, low complexity equipment are more commonly donated than large, highly complex devices (Fig. 2b). The survey presented the categories as options for the respondents, with examples for each category. The respondents decided which category their equipment fell in to.

The scale of operations varied considerably across organizations in terms of the frequency and size of shipments. There were also considerable differences in organizational structures and human resources. Most relied entirely on volunteers for day-to-day operations, with no paid staff. For example, one organization has a team of about 50 volunteers, with about half in the recipient country who receive small monthly stipends, and the rest in Canada or elsewhere. On the other hand, a minority of organizations have a mix of paid and volunteer staff 
a

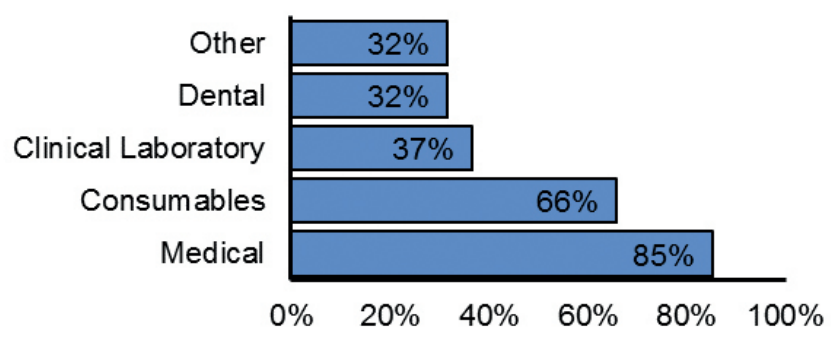

b Equipment Size/Complexity

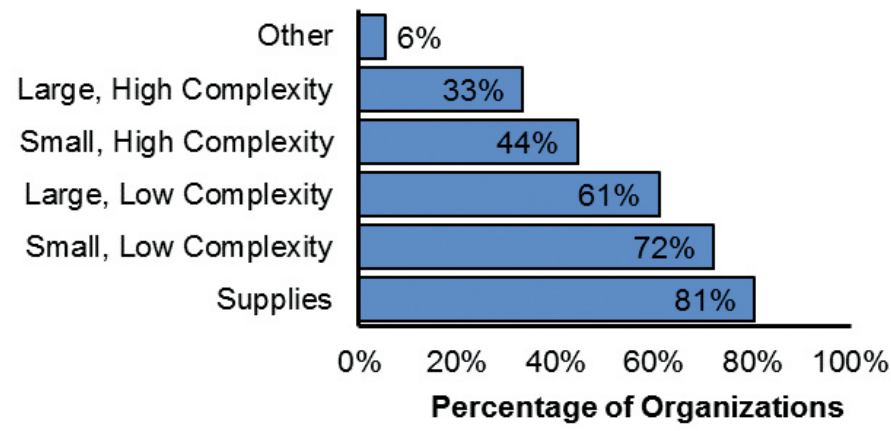

FIGURE 2. Percentage of organizations that reported donating (a) different types and (b) different sizes/complexity of equipment. In (a), the Other category includes mobility aids, pharmaceutical supplies and medicines, school supplies, vehicles (buses, ambulances), office furniture, computers, and funding (to support other organizations that donate equipment) $(n=41)$. In (b), the Other category includes medicines, vitamins and wound care supplies $(\mathrm{n}=36)$.

(e.g., one having ten paid full-time employees and about 40 volunteers, and another having one paid staff and a volunteer board of directors.

The next three sections summarize survey results on donor experiences related to three main phases of the donation process: consultation and communication with recipients, planning the donation process, and follow-up and monitoring.

\section{Consultation}

\section{How Recipients are Chosen}

Most organizations chose recipient countries organically, through personal connections or member suggestions. For example, two interviewees told stories of having visited a certain country where they noticed a great need. In one case, this experience led to the inception and founding of the organization. In many other cases, the recipient country reached out to an organization because of having heard about their charitable work. Another model that emerged for recipient selection (at least three organizations) was the existence of a 'sister organization' in the recipient country that could act as a partner for the donation initiative. In one case, the recipient cannot always be controlled because the organization relies on volunteers to bring supplies overseas and to find a suitable recipient upon arrival. Unfortunately, when relationships are formed informally, they can also easily dissolve. For example, one organization said that they will no longer work with certain countries due to poor experiences that made them not want to go back.

\section{Communication}

Another key element of a donation initiative is communication between all stakeholders involved. Fifty eight percent of 38 survey respondents said they communicate directly with the recipient hospital or clinic when planning a donation. With these cases of direct communication, the recipient contact person varied and included people involved in receiving/distribution, medical directors, and Ministry of Health representatives. One organization has local volunteers in the recipient country (1 to 3 per hospital) that help coordinate the donations and provide training to healthcare staff at the recipient hospitals.

For those Canadian organizations that do not communicate directly with the recipient hospital, their main point of contact was often another NGO working locally to coordinate the donation, or a sister or satellite branch of their own organization. Forty-seven percent reported communicating with a sister charity or organization and $44 \%$ with an independent organization in the recipient country. Only $31 \%$ reported they correspond with government officials in the recipient country. Other stakeholders included sister organizations in the US, religious groups, and equipment providers in the US. Sixty-one percent of organizations communicated with multiple stakeholder groups.

The most common mode of communication was email ( $94 \%$ of 35 responses), however in-person communication was also common (71\%). Telephone was used more 
than Skype (54\% versus 20\%), which could be indicative of widespread use of cellphones in low-resource settings and poor internet connections. One organization said they use shared file systems as a mode of communication (e.g., Dropbox and Google Drive) when planning a donation. Seventy-four percent of organizations rely on more than one mode of communication.

\section{Meeting Recipient Needs}

One of the most important stages in planning a donation is determining the needs of the recipient. Our interviews revealed many different needs assessment strategies employed by donor organizations. One organization has a system in place where potential recipients can submit a 'wish list' that the organization will try to fill. Another said they perform a thorough needs assessment and impact assessment in person every three months at each of the hospitals they work with; the organization's founder speaks directly with the health care staff (doctors and nurses) in every ward and asks what they think they need more than anything else. From this feedback, they produce a list of the most needed pieces of equipment. Other organizations tend to respond to requests from recipients; one stated the needs assessment process is a long email exchange with potential partners in which they determine whether the partner is serious, credible, and capable of receiving a container and getting the equipment to work; another said that they identify needs through a doctor that has actually travelled to the country.

Two of the organizations interviewed deal exclusively in mobility devices. In one case, an advocate in the recipient community (typically a school principal, mayor, doctor) prepares applications for each potential wheelchair recipient - hip size, length, what type of leg support is needed, etc. along with photos. The donor organization then works with the advocate who receives the shipment and coordinates getting the chairs to the right recipients. Another organization mentioned that they are not always able to match needs directly and, based on the available supply, will send a standard set of equipment in their shipments, whether the recipient country has indicated a specific need or not.

\section{Planning and the Donation Process}

While many individuals and organizations are highly motivated to provide aid where needed, all donors face significant challenges with the logistics of the donation process. Unfortunately, for many donors, these challenges can prevent donations from reaching their intended recipients.

\section{Equipment Sources}

Most organizations ( $62 \%$ of 37 responses) rely on several different sources for the equipment they donate to developing countries. For example, one organization stated in their interview that they collect equipment from hospitals, seniors' homes, private homes, and group homes. Another said about $75 \%$ of the equipment they send overseas is sourced from the US, some of it brand new but acquired at a considerable discount. Based on the survey responses, medical clinics and hospitals were the most common source of equipment (about half of the organizations sourced equipment from such places), however manufacturers, second-hand equipment vendors, seniors homes, other non-profit organizations, institutions such as universities and colleges, and individuals (mainly from home care situations) were also listed as sources of equipment. Pharmaceutical and drugstore companies also donate surplus pharmaceutical products such as pain killers, flu medication and burn gauze that are fully FDA regulated, newly packaged and have six months or more until expiration.

\section{Equipment Testing}

Once the equipment has been procured from their respective sources, some of the surveyed organizations conduct technical quality control and repairs before shipping to the recipient (Fig. 3a). The most common check was for power compatibility (63\% of 27 responses) and the least common was equipment calibration (30\%). Fifteen per cent of organizations performed no testing at all on the equipment they donate. Only 13 organizations ( $43 \%$ of 30 responses) reported having a volunteer or staff biomedical engineer available, which may have implications for the level of technical testing that is possible before equipment is shipped overseas. For example, two organizations shared in their interviews that they get 
volunteer technologists or engineers to inspect equipment as a quality control measure before it is shipped. One international organization relied on a workshop in their US location for repairs; they also partnered with a repair shop in the recipient country so that repairs could be done locally. Due to limited time, resources, and capacity some organizations reported that they are simply unable to perform any equipment testing.

\section{Shipping}

Most organizations surveyed ( $72 \%$ of 32 responses) send shipments in 20' or 40' foot containers by sea. The next most common form of shipping was via checked baggage of volunteers traveling to the recipient country (25\%) followed by air freight (19\%). Some organizations are able to send containers overseas monthly or every two months, while others send shipments annually. One organization estimated that they send 35 containers per year. It is also common that shipments are sent irregularly, for example, whenever a container is filled or when volunteers are traveling overseas and are able to take donations with them.

Shipping costs represent a major challenge for donor organizations when planning donations overseas. The surveyed organizations have reported shipping costs ranging from $\$ 4,000$ - \$12,000 CAD per shipment. These large sums of money are mostly gathered through fundraising efforts and sometimes through grant applications. In other cases, organizations have negotiated agreements with shipping companies to waive fees, arranged for embassies of the recipient countries to cover the costs of shipping, or even used connections to arrange for free transport between warehouses. One organization reported that in their case the recipient assumes the cost of shipping and that it depends on the organization whether they organize the shipping details or not. In an effort to help reduce overall shipping costs, it was reported in an interview that a Canadian shipping company offers complimentary domestic shipping of wheelchairs from any Canadian city to Vancouver (to then ship internationally). Unfortunately, donors often cannot transport the wheelchairs to the shipping company itself, so this service remains heavily underutilized. Another organization was able to arrange free air cargo transport of donations through a Canadian airline.

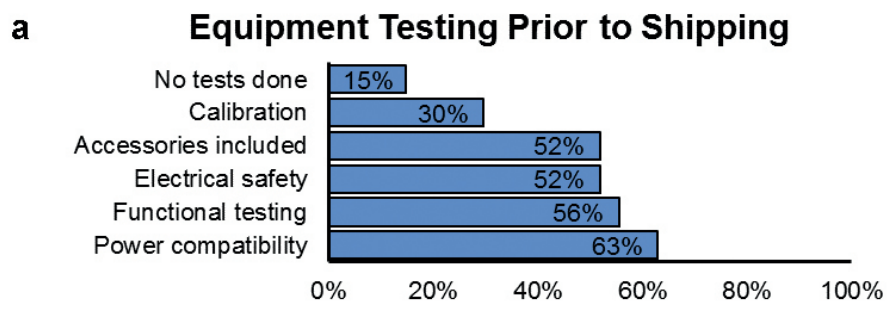

\section{b Supplementary materials or services}

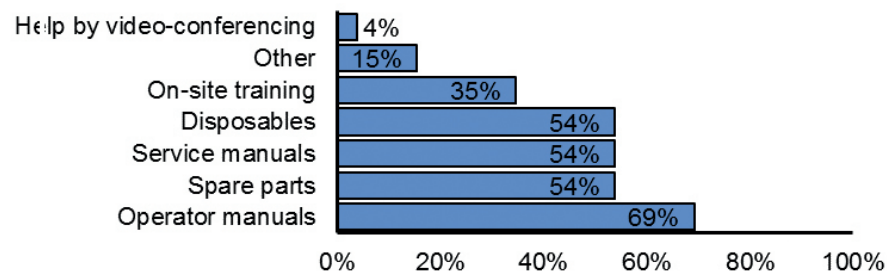

c Follow-up Information From Recipients

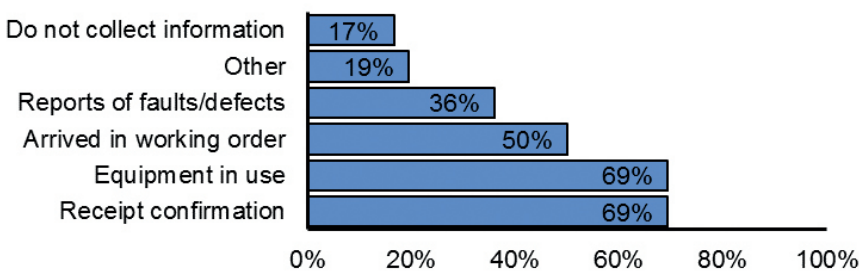

d

\section{Post-donation Requests}

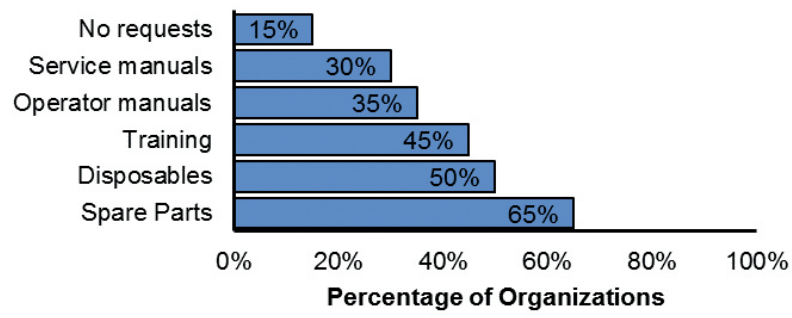

FIGURE 3. Percentage of surveyed organizations providing different types of support (a $\&$ b) before and (c $\&$ d) after shipping a donation. (a) Technical quality control prior to shipping, including compatibility with line voltage/frequency of destination country, functionality, electrical safety, completeness of accessories, and checking calibration against manufacturer specifications ( $\mathrm{n}=$ 27). (b) Supplementary materials or services provided with donated equipment $(n=27)$. Other includes packaged goods, donations, clothing, funding to support sustainable projects, and biomedical engineer visitations. (c) Information collected from recipients after the donated equipment has been delivered $(n=36)$. Other includes installation, follow-up onsite visitations, ongoing usage reports, and patient data. (d) Post-donation requests from recipients for additional support $(n=20)$. 


\section{Customs}

Once the equipment has successfully been shipped outside of Canada, the next major challenge is getting through customs. In addition to paying duties, differences in culture and infrastructure of the recipient country need to be considered. While some organizations prefer not to donate to countries if they are charged duty fees, others have partner organizations based in the recipient country who can negotiate the receipt of the equipment. Organizations that deal directly with customs have reported incidences of port officials expecting bribes or additional payment. For example, in one case an entire shipment had to be abandoned at the port because the cost of storage was greater than the value of the goods being shipped.

Donating organizations have found that shipping items that are available in the local market, such as clothing, can introduce difficulties with customs clearance due to the impact these products can have on the local economy. One organization said they try to purchase goods locally whenever possible in an attempt to provide cash flow to the recipient country, helping the local economy in a different way and avoiding custom fees and shipping.

\section{Regulatory and policy considerations}

Another challenge organizations face is deciding how to interpret Canadian Medical Device regulations drafted by Health Canada. ${ }^{9}$ As a result, some organizations have stopped donating altogether to avoid the issues of perceived liability. Others have created their own legal documents and have the recipients sign a medical release waiver when they accept the donated equipment.

\section{Support for Recipients}

In addition to donating medical equipment, many organizations provide additional support materials and services in order to ensure successful equipment usage. Operator manuals are the most common resource provided to recipients, but only about half of the organizations surveyed provide service manuals, spare parts, and disposables (Fig. 3b). One organization told us since not all manuals are available online, it is difficult for recipients to find them, further exacerbated by downloading issues due to poor network connections. This could also explain why so few organizations ( $4 \%$ of 27 responses) make use of video-conferencing as an additional mode of support.

Sending people overseas to help with the arrival, installation, and training of donated equipment is a challenge for many organizations due to the cost and time commitment involved, but some (35\%) are able to provide this extra support by one of the following ways:

- returning to the same country year-after-year and has established a three-week camp where they repair and help fit users to wheelchairs;

- providing training programs on how to use the equipment once it has been donated, and has contacts affiliated with their organization in the recipient country that play an ongoing role with equipment use and support;

- sending a team of biomedical technicians overseas around four to five times a year along with service manuals, and ensures that the equipment is fully serviced before shipping it out;

- sending volunteers overseas to help set up equipment (volunteers pay their own way).

\section{Follow-up and Monitoring}

The final stage in the donation process is long-term monitoring in order to measure the effectiveness of the donation. We asked organizations about the information they gather from recipients after a donation has been made, and whether or not they receive any follow-up requests from the recipients. Most of the surveyed organizations (70\% of 36 responses) request confirmation that the equipment was received and put into service, but only $50 \%$ verify that it arrived in good working condition (Fig. 3c). Even fewer (36\%) collect reports of equipment faults or failures after it is put into service. Seventeen per cent of survey respondents said they do not collect any information at all.

We learned from the interviews that while some organizations request formal documentation or reports confirming receipt and/or functionality of equipment, in general the feedback that many receive is informal (e.g., thank you notes, pictures of the equipment at its final destination) and sometimes indirect (e.g., newsletters of recipient organizations). One organization we interviewed 
was particularly committed to monitoring their effectiveness. They had a public health specialist conduct a program evaluation, identifying what their organization was doing well and where they were weak. Their commitment to data collection and transparency has helped them to improve their effectiveness as an organization. Another said they track each item they donate in case there is a manufacturer recall, in which case they are able to notify the recipient country.

Another measure of the effectiveness of a donation is the extent to which the recipient requests additional support and/or materials (Fig. 3d). The most common follow-up request is for spare parts (which is consistent with our findings from the survey of recipients in Ghana summarized in 3.2 Recipient Perspective) followed by disposables and training. As discussed above, not all organizations include operator and user manuals with their donations, and so it is perhaps not a surprise that these manuals are often requested. Only three surveyed organizations (15\% of 20 responses) reported that they did not receive any additional requests from recipients.

\section{Recipient Perspective}

Surveys with stakeholders at 28 hospitals in Ghana provided valuable insight into the recipient perspective with respect to medical equipment donations. Note that not all of these hospitals necessarily received donations from Canadian organizations.

\section{Consultation}

\section{Communication}

An important element of the equipment donation process that we wanted to learn about was communication between donors and recipients, particularly when it came to the identification of equipment needs. When asked about the last donation received, $96 \%$ of respondents reported that there was communication with the donor agency before the donation was shipped, and 86\% reported that the donor discussed their needs or asked what their greatest needs were in advance. Equipment needs were requested or identified in several different ways, either through a form or survey given by the donor (18\%), a wish list submitted in advance by the recipient hospital (18\%), or simply via direct communication between the donor and hospital administrators (11\%). In a couple of cases $(7 \%)$, a representative of the donor organization came to the hospital to discuss the needs of the hospital in person.

\section{Meeting Recipient Needs}

Two-way communication between the donor and recipient to identify needs prior to delivery is extremely important for a donation to be effective. $7 \%$ of respondents added that this communication enabled them to make additional requests, some for very specific parts (e.g. fuses), allowing them to better operate medical devices they already had. The communication of equipment needs, however, did not always result in needs being met. One hospital mentioned that despite supplying a list of needed equipment, those items were not included in the shipment. $11 \%$ said they were not consulted at all about the equipment they needed, and one hospital commented that they had received a "surprise package"

\section{Planning and the Donation Process}

\section{Equipment Testing}

All recipient hospitals reported that donated equipment typically arrives in working condition, however $25 \%$ said they had received donations in the past that were missing accessories essential to the operation of the device, and $18 \%$ had received equipment that was faulty. For equipment that does arrive in working condition, $61 \%$ of respondents estimated that it lasts less than two years before breaking down. Although $46 \%$ of hospitals said they can often repair broken equipment, repairs can take weeks or even months depending on the parts and or expertise required.

\section{Support for Recipients}

Upon receipt of donated medical equipment, most donor organizations provide on-site installation of equipment, verification of functionality, and user training. On-site service training was less commonly provided (Fig. 4). The types of support provided were installation, verification, user training and service training with service training providing the least support (Fig. 4d) and verification the greatest support (Fig 4b).

When asked about common problems encountered with medical equipment donations, the most common 


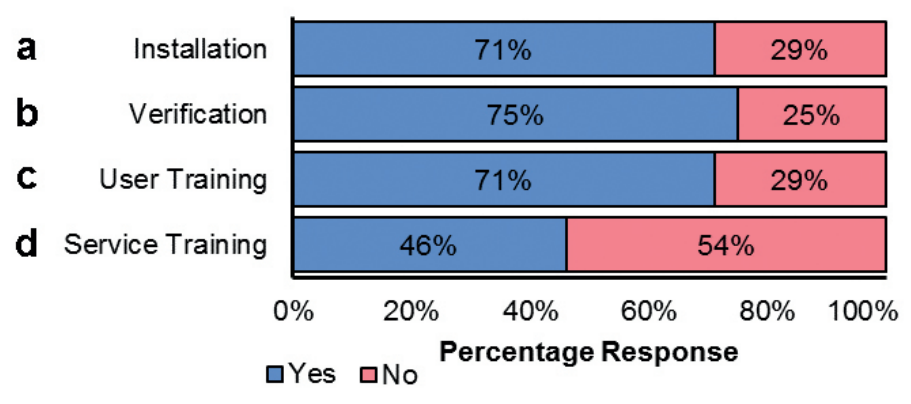

FIGURE 4. On-site support for donated equipment - Recipient facilities $(n=28)$ were asked if donor organizations provided (a) installation assistance, and (b) verification of functionality. They were also asked if donor organizations provided (c) user training, and (d) service training. Yes $=$ blue, No $=$ red. Recipient responses are given as a percentage.

problem mentioned was a lack of spare parts (57\%), followed by lack of operating and/or service manuals (32\%) and issues with consumables, either lacking or expired (21\%). These percentages are based on responses to an open-ended question. For example, Figure 5 shows the percentage of recipients who reported that the received donations included spare parts, and whether spare parts were available locally. All responses were either some or none (Fig. 5).

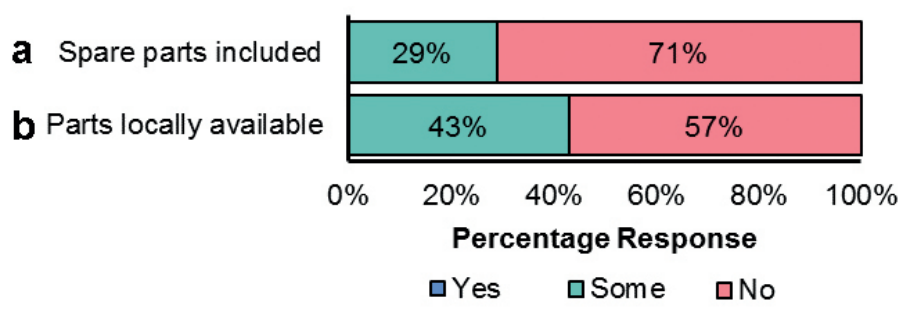

FIGURE 5. Availability of spare parts. Percentage of surveyed recipient hospitals $(n=28)$ that reported (a) donations included spare parts, and (b) spare parts were locally available. Yes = blue, Some but not all $=$ green, No $=$ red .

Figure 6 shows that less than $35 \%$ of recipients always receive operating manuals, service manuals, consumables or accessories. Other common problems encountered included: power issues (e.g., the equipment was meant for the wrong voltage, or was too sensitive to power fluctuations), or the equipment was not durable or appropriate for the setting (e.g., the climatic conditions impaired the functioning of some equipment).

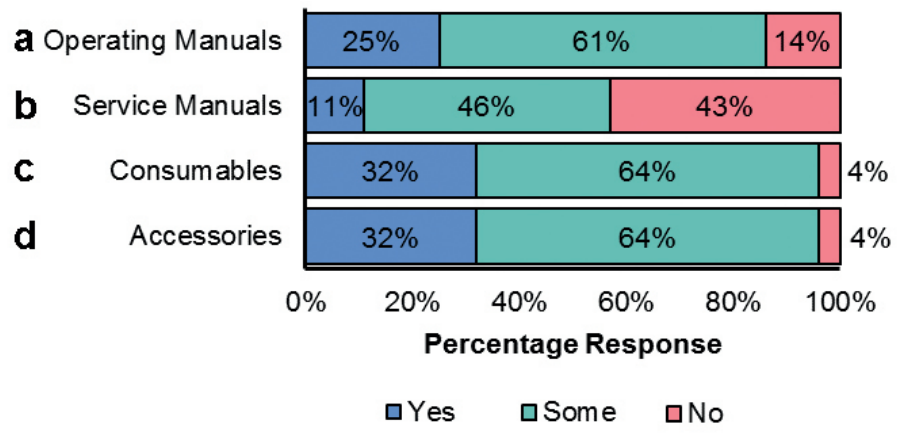

FIGURE 6. Support materials for donated equipment. Percentage of surveyed recipient hospitals $(n=28)$ that reported receiving (a) operating manuals, (b) service manuals, (c) consumables, and (d) accessories with donated equipment. Yes $=$ blue, Some but not all = green, No = red.

\section{Recipient Feedback}

Recipients were also asked to describe in their own words what they thought could be done to improve the effectiveness of medical equipment donations to Ghana. The following are some illuminating responses:

- "Thorough needs assessments of beneficiary facilities should be done. Equipment donated must meet these needs."

- "All donations must go with initial user trainings and monitoring by the donors as to the functionality of the equipment."

- "Should make available consumables and if possible link users to sources of this items they can be procured by users when it's finished."

- "Tax exemptions on these equipment. Removal of bureaucratic barriers."

Despite the challenges and common problems encountered, when asked whether donated medical equipment benefited their organization $100 \%$ responded positively. Donated electronic medical equipment allowed greater efficiency and accuracy for diagnosis, therefore reducing the burden on the nurses and staff, and allowing for better quality of care. $48 \%$ of respondents answered that donated equipment helped in cost reduction, with $51 \%$ stating that donated supplies either reduced the burden on health care providers or helped with patient management. Furthermore, one of the facilities noted that 
medical equipment allowed for reduction in premature fetal mortality rates.

\section{DISCUSSION AND NEXT STEPS}

Over 40 organizations and hundreds of volunteers across Canada are involved in the donation of medical equipment to developing countries. We have found that these organizations varied considerably in terms of the size of their operation, the types of equipment donated and the processes they follow when carrying out a donation initiative.

There are many resources available to help donor organizations effectively plan and execute all of the phases of a donation activity. ${ }^{2,10,11,12,13,14}$ These resources cover everything from deciding whether to donate to how to deal with international shipments to putting equipment into service at the recipient institution. A common theme in all the published guidelines on equipment donations is the importance of three core elements (Fig. 7): (a) consultation - ensuring that the needs of the recipient are well understood and have been established through communication with all parties involved; (b) planning and process - having a clear donation plan identified and agreed to in advance by all stakeholders, including comprehensive quality assurance assessments; and (c) monitoring and follow-up - developing a sustained and supportive relationship with the recipient institution,

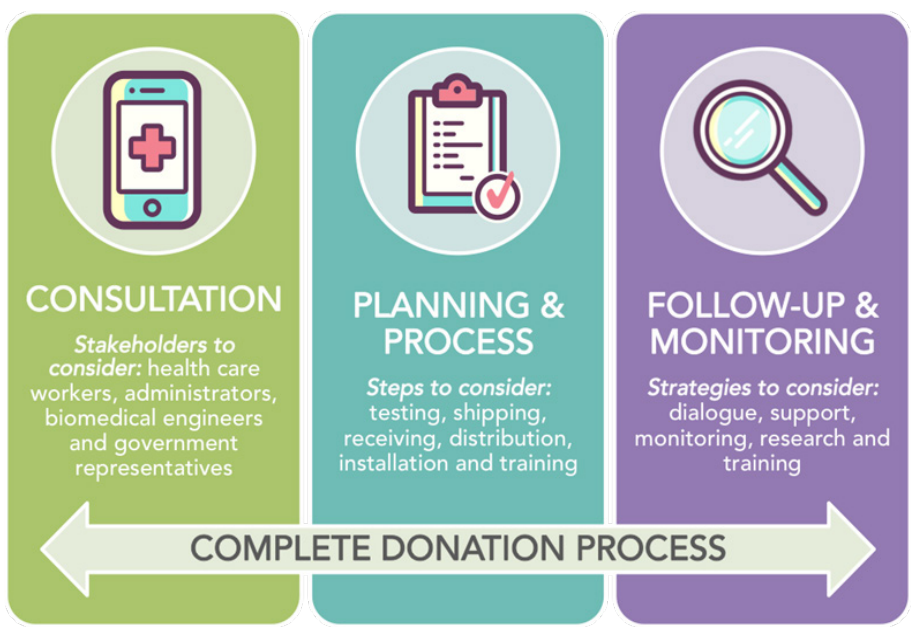

FIGURE 7. Three main phases of a medical donation process. Consultation, Planning \& Process, and Follow-up \& Monitoring . ensuring long-term success and impact We have created a video which clarifies the benefits of including these core elements in the donation process. ${ }^{10}$

We have found through this study that many Canadian organizations find it challenging to adhere to such guidance due to limited staff and financial resources.

\section{Donation Strengths and Opportunities for Improvement}

Most Canadian organizations appear to be doing well at identifying needs and communicating with a wide range of stakeholders in the recipient country - including healthcare workers, representatives from the Ministry of Health, and sister or local charities - when planning a donation. The recipient survey corroborated this finding as well, with the majority of respondents reporting their needs were discussed with the donor in advance. There is also much evidence of how these different Canadian organizations are having a positive impact on the communities in which they work, for example, providing wheelchairs and other mobility aids to help people to become more active members of their community, or training local staff to repair \& maintain wheelchairs. Working with sister organizations in recipient countries helps the sister organization to continue actively working in their communities. Despite these strengths, however, there are still opportunities for improvement (Fig. 8).

In the area of planning and process, we found that donor organizations had limited written policies and procedures to guide and govern their operations (e.g., only one interviewed organization had developed standard operating procedures (SOPs), and very few had systems in place for documentation). Formalizing procedures is a widely accepted practice in well-run organizations. Documenting every step in a process helps maintain quality and ensures that consistent practices are followed. (e.g. one organization uses a computerized inventory system such that boxes leaving a warehouse can be scanned and removed from inventory automatically; another organization uses an online tool, Google Forms, to solicit and track equipment donations.)

Based on our survey, we found a general lack of comprehensive quality assurance testing before equipment is shipped. Recipients reported incompatible voltage, 
faulty equipment, and missing accessories as common problems, which could have been mitigated with proper inspection and testing. The fact that $57 \%$ of organizations did not have a volunteer or staff biomedical engineer to help with testing represents an opportunity for the biomedical engineering community in Canada to become more involved and engage with donor organizations to help improve the effectiveness of donations.

Canadian organizations can also improve when it comes to providing additional support with equipment donations in the form of operator and service manuals, spare parts, accessories and training. Spare parts in particular were the number one follow-up request from recipients (according to donors), and the number one problem encountered by recipients in Ghana.

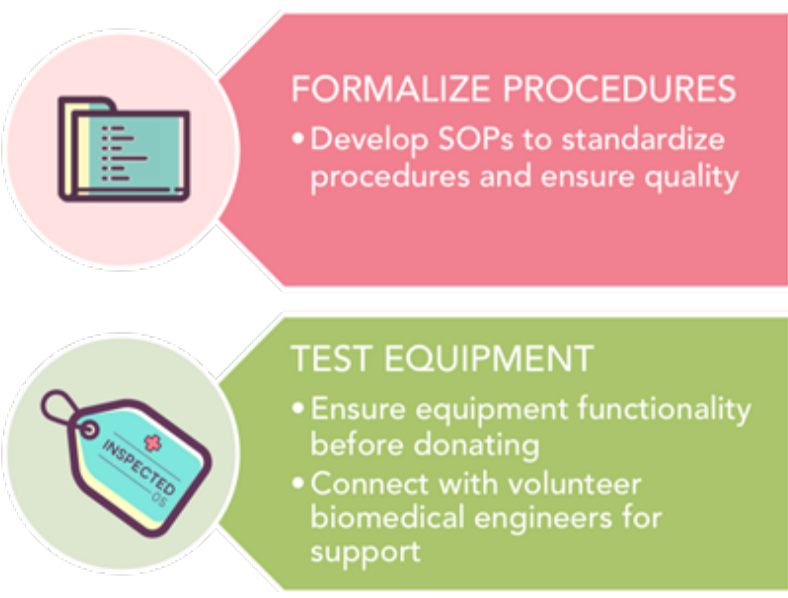

When it comes to monitoring and evaluation, in general there is a lack of information sharing post-donation about short-term and long-term equipment functionality. This means that most organizations cannot measure the success of their donations or the impact they are having in the recipient countries. It was apparent from our interviews that organizations that have developed a long-term relationship with a particular recipient and return to the same location year after year are better able to monitor progress and identify issues, even without any formal feedback system.

Donors should be formally requesting feedback, and recipients should be proactive in communicating how well things are working, so that both parties can mutually track donation effectiveness. This process is facilitated when a
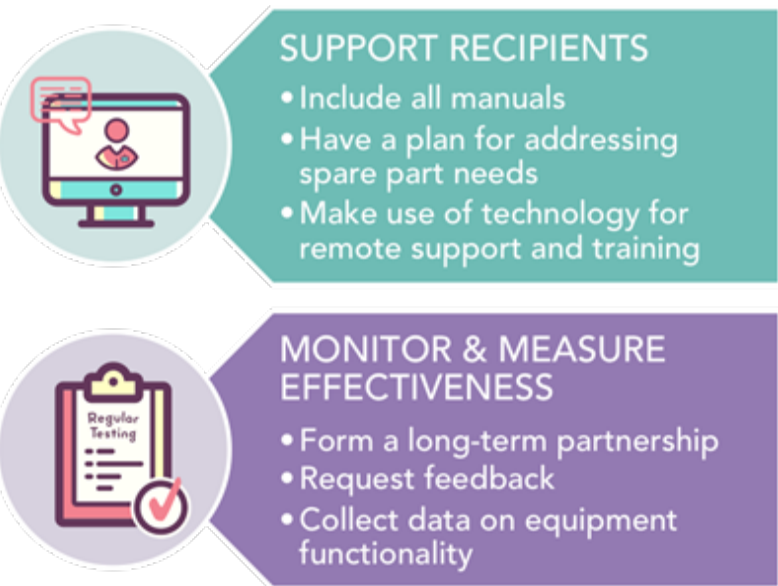

MONITOR \& MEASURE EFFECTIVENESS

- Form a long-term partnership

- Request feedback

- Collect data on equipment

functionality

FIGURE 8. Four main areas of improvement for Canadian organizations to focus on: formalizing procedures through documentation, better equipment testing prior to shipping, better long-term support for recipients, and monitoring that includes evaluating donation impact.

long-term partnership is formed between the donor and recipient, and the donation is not a one-off transaction.

The wide range of capabilities among donor organizations suggests an opportunity to share knowledge and best practices, so that they can learn from each other and better address the four areas for improvement as shown in Fig. 8.

\section{Recommendations}

Based on the disparities in practices observed in Canadian donor organizations, and the disparities in resources available, it would be beneficial for all donor organizations to communicate and collaborate with one another when planning donations overseas (Fig. 9). There could also be opportunities to economize (e.g., sharing a shipping container), improve the matching of available equipment with known needs, or share resources (e.g., volunteers, engineering expertise), to improve the efficiency of operations. It would also be beneficial for organizations to share their donation experiences and challenges with one another (positive and negative) so that others can learn from them, especially if they are doing something innovative. It may be beneficial to create a network for such communication, for example many Internet based tools are available that could facilitate building such a community for the sharing of information. 




FIGURE 9. Donation Community in Canada. Individuals, groups of volunteers, and small and large organizations across Canada collectively have valuable knowledge and experience that could benefit others engaged in donation work. Better communication, collaboration, and sharing of resources and expertise among these groups could lead to more effective donation practices for everyone and better impact globally.

Lastly, since many organizations do not have the resources or volunteers available to travel to recipient destinations to help with equipment installation, training and maintenance, innovative solutions to the challenge of long-distance equipment support and maintenance are needed. While most organizations are able to use email for basic communications, other tools such as WhatsApp, Viber, or file-sharing applications such as Dropbox or Google Drive, which are not bandwidth-heavy or do not require constant internet connections, could be used more frequently to help plan and support donations and share resources.

\section{CONCLUSION}

Thanks to the generous donations of Canadian charities and non-profit organizations, almost 50 countries around the globe have received critical medical equipment to help improve the delivery of healthcare and support healthy communities. Through this study, we found that these donations have provided everything from simple frontline equipment such as blood pressure monitors and pulse oximeters, to MRI and x-ray machines.. The donation process presents challenges to donating organizations, most significantly in shipping equipment, passing customs barriers, ensuring compatibility of equipment, and providing support for recipients. Based on our interviews with hospitals in Ghana, the most prominent recipient challenges include a lack of spare parts, access to service manuals, and replenishment of consumable items. To overcome the challenges for both parties, successful donor practices include consultation with recipient countries to ensure needs are met, careful planning of the entire donation process to provide a clear plan, and finally monitoring and follow-up to facilitate long term success. We strongly believe that more effective collaboration and communication between Canadian donor organizations would reap tremendous benefits for recipient countries, and create opportunities to economize and improve the effectiveness of medical equipment donations.

\section{ACKNOWLEDGEMENTS}

Project partners include: The International Outreach Committee of the Canadian Medical and Biological Engineering Society (CMBES); Food for the Hungry, Canada; Centre for Global Engineering, University of Toronto; and the Ghana Biomedical Engineering Association (GBEA), with whom the CMBES has had an ongoing partnership. Shahrzad Mirzazadeh is acknowledged for conducting the survey and interviews in Canada. We gratefully acknowledge all the Canadian organizations that participated in our survey and/or interviews, as well as the health professionals in Ghana that provided responses to our recipient survey. This work was carried out with the aid of a grant from the International Development Research Centre, Ottawa, Canada.

\section{COMPLIANCE WITH ETHICAL STANDARDS}

\section{Ethical approval}

Informed consent was obtained from all individual participants included in the study.

\section{Conflict of interest}

The authors declare that they have no conflict of interest. 


\section{REFERENCES}

1. Dyro JF. Donation of Medical Device Technologies. Clinical Engineering Handbook. Elsevier Academic Press; 2004. pp. 155-158.

2. World Health Organization. Medical device donations: considerations for solicitation and provision. In: World Health Organization [Internet]. 2011 [cited 11 Oct 2018]. Available: http://apps.who.int/iris/bitstr eam/10665/44568/1/9789241501408_eng.pdf

3. Perry L, Malkin R. Effectiveness of medical equipment donations to improve health systems: how much medical equipment is broken in the developing world? Med Biol Eng Comput. 2011;49: 719-722.

4. World Health Organization. Guidelines for Health Care Equipment Donations [Internet]. 2000 Mar. [Cited 11 Oct 2018] Available: http://apps.who.int/iris/ bitstream/10665/70806/1/WHO_ARA_97.3_eng.pdf

5. Zomboko FE, Tripathi SK. Challenges in Procurement and Use of Donated Medical-Equipments: Study of a Selected Referral Hospital in Tanzania. Researchers World. Educational Research Multimedia \& Publications; 2012;3: 41.

6. Howie S, Stephen H. Beyond good intentions: lessons on equipment donation from an African hospital. Bull World Health Organ. 2008;86: 52-56.

7. Authors, A Canadian-Ghanaian partnership for improving health technology management. 7th International
Conference on Appropriate Healthcare Technologies for Developing Countries. 2012. doi:10.1049/cp.2012.1469

8. Charities and giving [Internet]. 17 Jun 2007 [cited 11 Oct 2018]. Available: http://www.cra-arc.gc.ca/ charitiesandgiving/

9. Canadian Medical Devices Regulations. In: Government of Canada, Justice Laws Web Site [Internet]. 17 Jul 2016 [cited 11 Oct 2018]. Available: http://laws-lois.justice. gc.ca/eng/regulations/sor-98-282/

10.CMBES Donations Video [Internet]. Youtube; 2015. [cited 11 Oct 2018] Available: https://www.youtube. com/watch?v=R27CPPAwL1Y\&feature=youtu.be

11. Mullally S. Making it Work: A toolkit for medical equipment donations to low-resource settings [Internet]. 2013 [cited 11 Oct 2018]. Available: https://www. thet.org/wp-content/uploads/2017/08/THET_MakingItWork_Toolkit_Final_Online.pdf

12. Keller K. PQMD GUIDELINES FOR QUALITY MEDICAL PRODUCT DONATIONS [Internet]. The Partnership for Quality Medical Donations; 2016. [cited 11 Oct 2018] Available: http://www.pqmd.org/wp-content/ uploads/2015/07/PQMD-Standard-V5-April-2016.pdf

13. BMET Digital Library [Internet]. [cited 11 Oct 2018]. Available: http://library.ewh.org/

14.Frank's Hospital Workshop [Internet]. [cited 11 Oct 2018]. Available: http://www.frankshospitalworkshop. com/index.html 